\title{
A Detailed Review On Medical Image Compression
}

\author{
Amit Verma ${ }^{1}$ \\ ${ }^{1}$ Department of Computer Science \& Engineering,Chandigarh University, Gharuan, Mohali, Punjab, 140413
}

Article History: Received: 11 January 2021; Accepted: 27 February 2021; Published online: 5 April 2021

Abstract:The current article is a scientometric analysis of the research articles on the topic "Medical Image Compression". Scopus and WoS databases have been used for downloading the papers related to the above discussed topic. PRISMA guideline have been used for the selection of the articles. A total 884 articles have been downloaded and 397 have been selected and analyzed with VOS viewer.

Keywords: Review, Scientometric, Medical Image Compression

\section{Introduction}

At exponential rates, the amount of medical data is increasing and equals the decrease in digital data storage costs or exceeds them. Although methods for compressing image data are available reversibly, existing methods minimize storage requirements only modestly [1], [2]. Irreversible compression can achieve dramatically higher compression ratios without any image loss. These are regularly used in teleradiology and also in the archiving and correspondence processes of images. To optimize the treatment procedures, the doctor must consider how these compression methods operate and the extent of the deterioration that happens. The technology and artefacts used widely in irreversible medical image compression. There is growing regular volume of image data produced in healthcare, especially in combination with the enhanced scan resolutions and the importance of volumetric image sets[3], [4]. The handling of these images makes the encoding, archival and transmitting techniques more effective. The current article is a bibliometric review which attempts to analyze the work done in the field of Medical Image Compression[5], [6] by analyzing the work done in the field of MIC (Medical Image Compression).

\section{METHODOLOGY}

PRISMA guidelines have been used for the selection of the papers. 884 papers have been downloaded from Scopus and Web of Science databases using the Boolean "Medical" AND "Image" AND "Compression". After applying the Prisma guidelines only 397 papers have been selected for the analysis purpose.

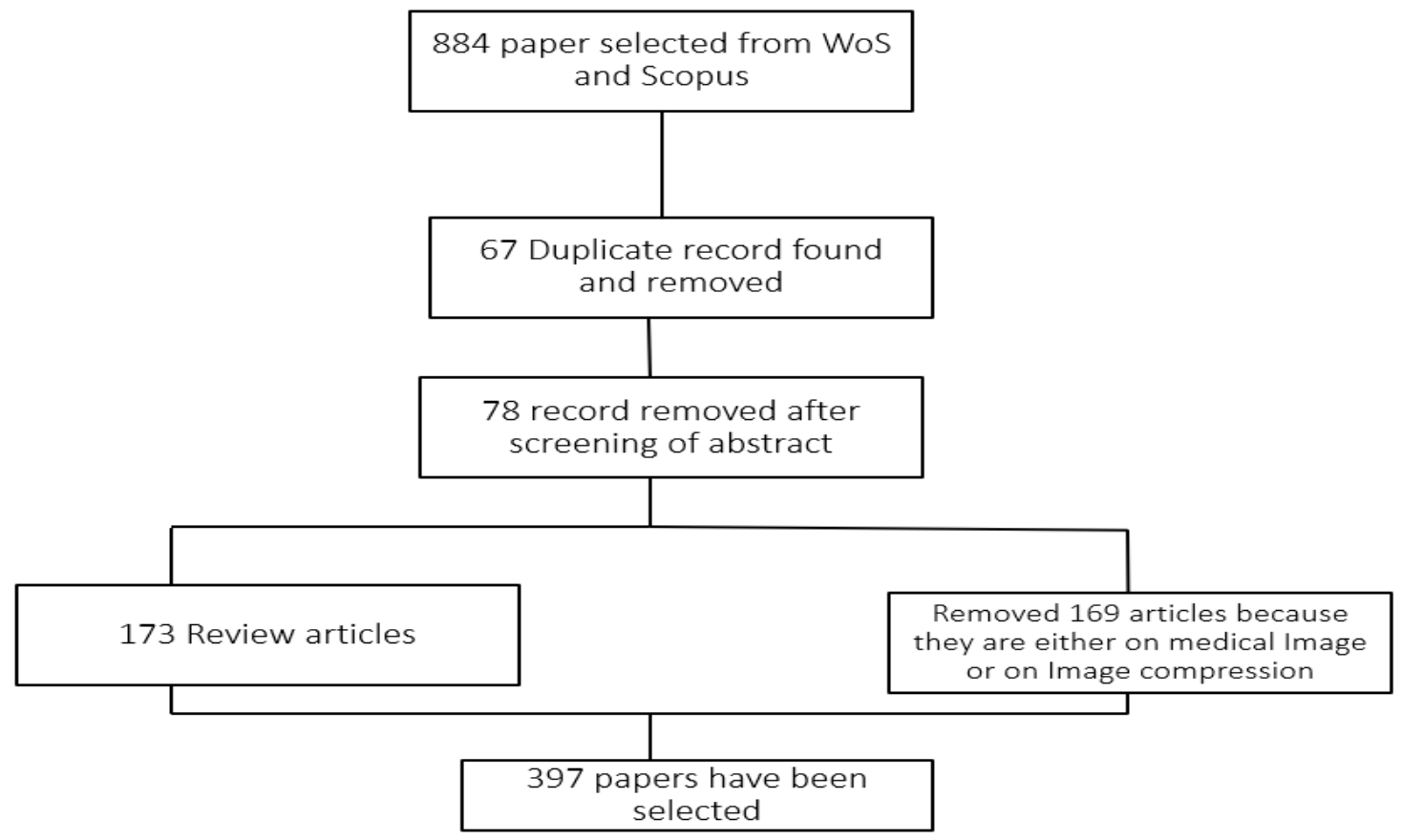

Fig.1. PRISMA Framework

\section{ANALYSIS}

Figure 2 shows the keywords used by the researchers in their manuscripts. Image compression, medical image compression, medical image processing are the keywords used prominently in the research articles. Table 1 reveals the different keywords and the number of occurrences for those. 


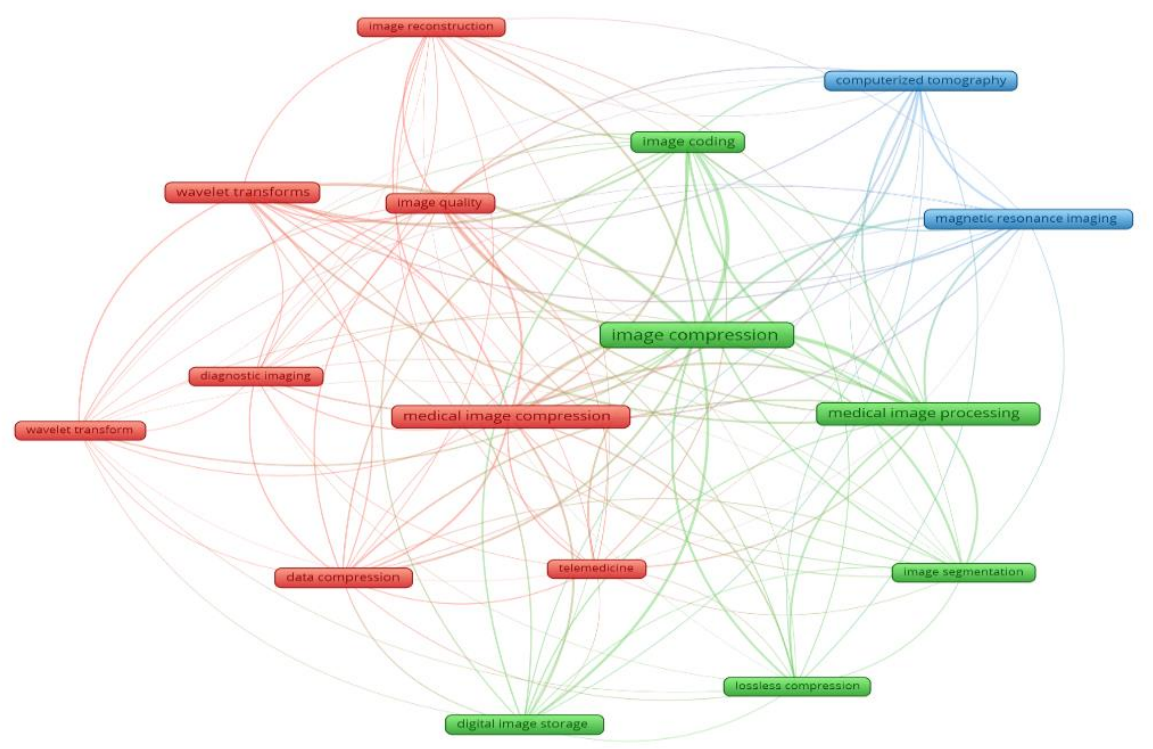

Fig.2. Medical Image Compression Keywords Analysis

\begin{tabular}{|r|l|r|}
\hline \multicolumn{1}{|c|}{ Sl.N } & keyword & \multicolumn{2}{c|}{ ces } \\
\hline \multicolumn{1}{|c|}{} & computerized tomography & 43 \\
\hline 1 & data compression & 50 \\
\hline 3 & diagnostic imaging & 29 \\
\hline 4 & digital image storage & 42 \\
\hline 5 & image coding & 99 \\
\hline 6 & image compression & 267 \\
\hline 7 & image quality & 69 \\
\hline 8 & image reconstruction & 33 \\
\hline 9 & image segmentation & 33 \\
\hline 10 & lossless compression & 37 \\
\hline 11 & magnetic resonance imaging & 56 \\
\hline 12 & medical image compression & 113 \\
\hline 13 & medical image processing & 146 \\
\hline 14 & telemedicine & 28 \\
\hline 15 & wavelet transform & 23 \\
\hline 16 & wavelet transforms & 87 \\
\hline
\end{tabular}

Table.1. Medical Image Compression Keywords Data

Figure 3 shows the source wise citation for the articles. Proceedings of spie - the international society for optical engineering and ieee transactions on medical imaging got the maximum citations but annual international conference of the ieee engineering in medicine and biology - proceedings published the second maximum number of manuscripts. 


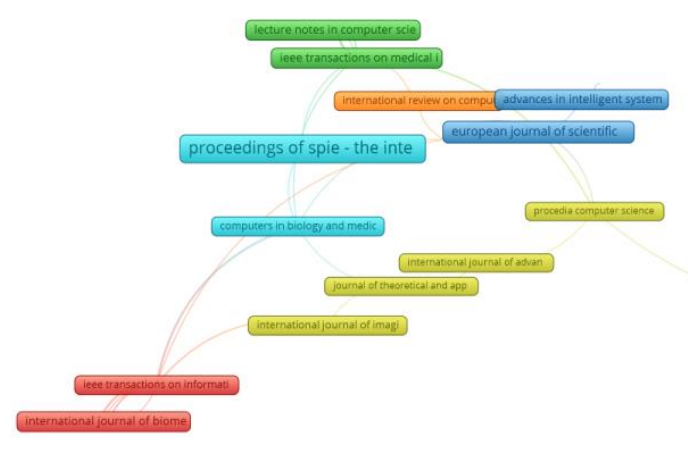

Fig.3. Medical Image Citation Source wise Analysis

\begin{tabular}{|c|c|c|c|}
\hline Sl. & source & $\begin{array}{l}\text { docum } \\
\text { ents }\end{array}$ & s citation \\
\hline 1 & proceedings of spie - the international society for optical engineering & 28 & 142 \\
\hline 2 & $\begin{array}{l}\text { annual international conference of the ieee engineering in medicine } \\
\text { and biology - proceedings }\end{array}$ & 10 & 54 \\
\hline 3 & european journal of scientific research & 7 & 37 \\
\hline 4 & advances in intelligent systems and computing & 6 & 9 \\
\hline 5 & ieee transactions on medical imaging & 6 & 264 \\
\hline 6 & international journal of biomedical engineering and technology & 6 & 9 \\
\hline 7 & $\begin{array}{l}\text { lecture notes in computer science (including subseries lecture notes in } \\
\text { artificial intelligence and lecture notes in bioinformatics) }\end{array}$ & 6 & 7 \\
\hline 8 & progress in biomedical optics and imaging - proceedings of spie & 6 & 30 \\
\hline 9 & international journal of applied engineering research & 5 & 0 \\
\hline 10 & international journal of electrical and computer engineering & 4 & 24 \\
\hline 11 & international review on computers and software & 4 & 11 \\
\hline 12 & journal of advanced research in dynamical and control systems & 4 & 6 \\
\hline 13 & journal of medical imaging and health informatics & 4 & 10 \\
\hline 14 & $\begin{array}{l}2012 \text { ieee-embs conference on biomedical engineering and sciences, } \\
\text { iecbes } 2012\end{array}$ & 3 & 10 \\
\hline 15 & $\begin{array}{l}2019 \text { international conference on wireless communications, signal } \\
\text { processing and networking, wispnet } 2019\end{array}$ & 3 & 0 \\
\hline 16 & computers in biology and medicine & 3 & 76 \\
\hline 17 & current medical imaging reviews & 3 & 21 \\
\hline 18 & electronics letters & 3 & 7 \\
\hline 19 & ieee international conference on image processing & 3 & 24 \\
\hline 20 & ieee transactions on information technology in biomedicine & 3 & 142 \\
\hline 21 & ifmbe proceedings & 3 & 1 \\
\hline 22 & international journal of imaging systems and technology & 3 & 6 \\
\hline 23 & journal of ambient intelligence and humanized computing & 3 & 4 \\
\hline 24 & journal of computer science & 3 & 11 \\
\hline 25 & journal of digital imaging & 3 & 22 \\
\hline 26 & proceedings - international conference on image processing, icip & 3 & 13 \\
\hline 27 & arpn journal of engineering and applied sciences & 2 & 2 \\
\hline 28 & bioengineering, proceedings of the northeast conference & 2 & 2 \\
\hline 29 & cluster computing & 2 & 8 \\
\hline 30 & communications in computer and information science & 2 & 4 \\
\hline 31 & data compression conference proceedings & 2 & 4 \\
\hline
\end{tabular}




\begin{tabular}{|c|c|c|c|}
\hline 32 & ieee international symposium on information theory - proceedings & 2 & 0 \\
\hline 33 & indonesian journal of electrical engineering and computer science & 2 & 0 \\
\hline 34 & international conference on signal processing proceedings, icsp & 2 & 3 \\
\hline 35 & $\begin{array}{l}\text { international journal of advanced trends in computer science and } \\
\text { engineering }\end{array}$ & 2 & 9 \\
\hline 36 & international journal of control theory and applications & 2 & 0 \\
\hline 37 & $\begin{array}{l}\text { international journal of innovative technology and exploring } \\
\text { engineering }\end{array}$ & 2 & 0 \\
\hline 38 & international journal of signal and imaging systems engineering & 2 & 6 \\
\hline 39 & $\begin{array}{l}\text { international journal of wavelets, multiresolution and information } \\
\text { processing }\end{array}$ & 2 & 3 \\
\hline 40 & journal of electrical engineering and technology & 2 & 12 \\
\hline 41 & journal of medical engineering and technology & 2 & 30 \\
\hline 42 & journal of theoretical and applied information technology & 2 & 2 \\
\hline 43 & lecture notes in computational vision and biomechanics & 2 & 0 \\
\hline 44 & lecture notes in electrical engineering & 2 & 18 \\
\hline 45 & medical physics & 2 & 43 \\
\hline 46 & optical engineering & 2 & 13 \\
\hline 47 & procedia computer science & 2 & 27 \\
\hline 48 & proceedings - ieee symposium on computer-based medical systems & 2 & 1 \\
\hline 49 & $\begin{array}{l}\text { proceedings - international conference on computational intelligence } \\
\text { and multimedia applications, iccima } 2007\end{array}$ & 2 & 16 \\
\hline 50 & proceedings - international conference on pattern recognition & 2 & 5 \\
\hline 51 & $\begin{array}{l}\text { proceedings of } 2005 \text { international symposium on intelligent signal } \\
\text { processing and communication systems, ispacs } 2005\end{array}$ & 2 & 11 \\
\hline 52 & $\begin{array}{l}\text { proceedings of the } 2 \text { nd international conference on smart systems and } \\
\text { inventive technology, icssit } 2019\end{array}$ & 2 & 0 \\
\hline 53 & proceedings of the sice annual conference & 2 & 13 \\
\hline 54 & shanghai jiaotongdaxuexuebao/journal of shanghai jiaotong university & 2 & 3 \\
\hline 55 & studies in health technology and informatics & 2 & 4 \\
\hline
\end{tabular}

\section{Table.2. Medical Image Citation Source wise Data}

The next figure portray the country wise citation. Kit can be observed from the figure and Table below that India got the maximum number of citations along with USA, China and Taiwan.

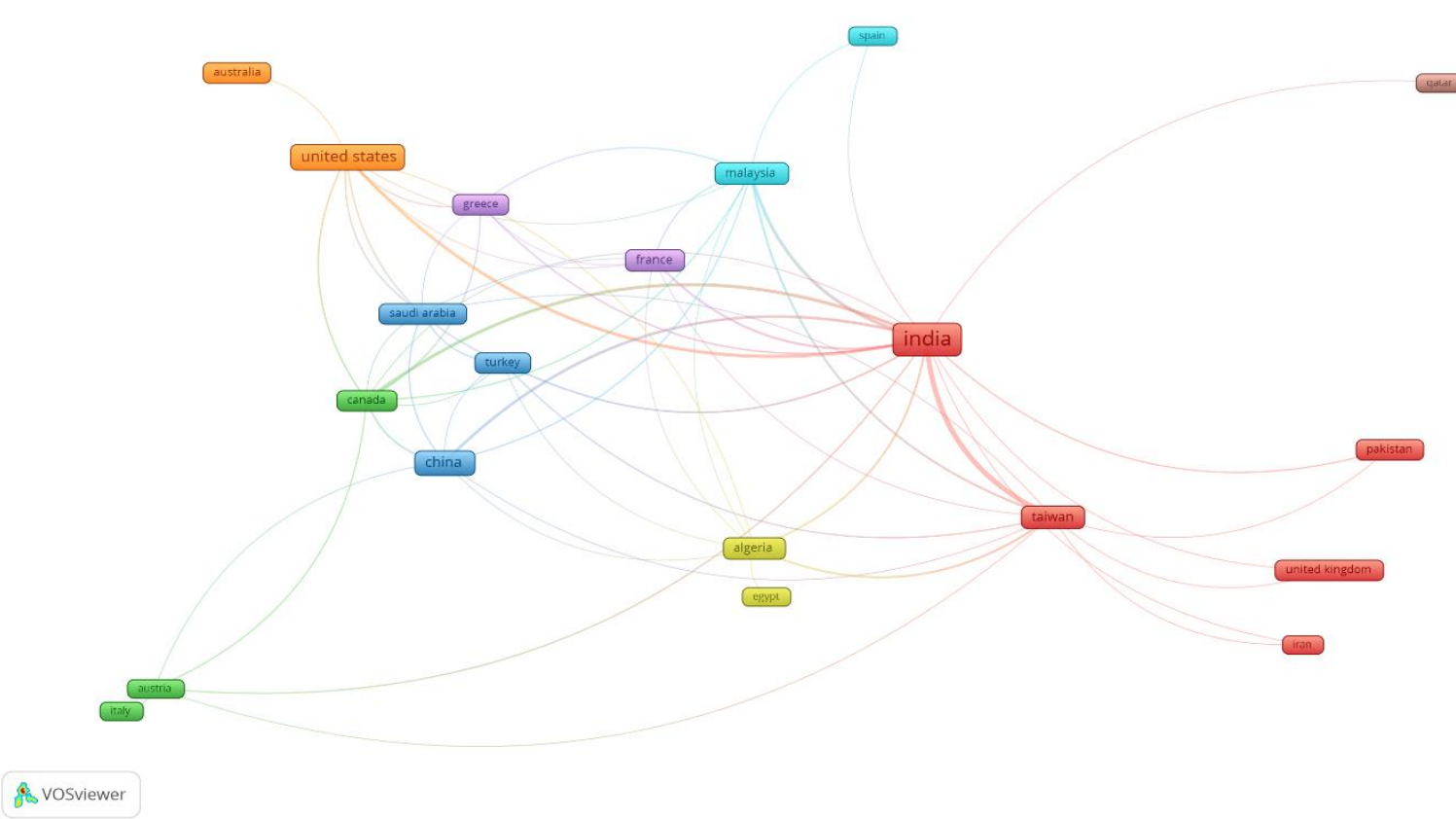

Fig.4. Medical Image Citation Country wise Analysis 


\begin{tabular}{|c|c|c|}
\hline Sl.No & country & documents \\
\hline 1 & India & 160 \\
\hline 2 & United States & 44 \\
\hline 3 & China & 39 \\
\hline 4 & Taiwan & 19 \\
\hline 5 & Malaysia & 18 \\
\hline 6 & France & 15 \\
\hline 7 & Algeria & 14 \\
\hline 8 & Canada & 9 \\
\hline 9 & Greece & 7 \\
\hline 10 & $\begin{array}{l}\text { United } \\
\text { kingdom }\end{array}$ & 7 \\
\hline 11 & Saudi Arabia & 6 \\
\hline 12 & Australia & 5 \\
\hline 13 & Pakistan & 5 \\
\hline 14 & South korea & 5 \\
\hline 15 & Thailand & 5 \\
\hline 16 & Turkey & 5 \\
\hline 17 & Indonesia & 4 \\
\hline 18 & Italy & 4 \\
\hline 19 & Qatar & 4 \\
\hline 20 & Spain & 4 \\
\hline 21 & Austria & 3 \\
\hline 22 & Egypt & 3 \\
\hline 23 & Iran & 3 \\
\hline 24 & Ireland & 3 \\
\hline
\end{tabular}

Table.3. Medical Image Citation Country wise Data

The data of co-authorship also reveals that the India have the most number of co authorship on the research papers on the Medical Image Compression.

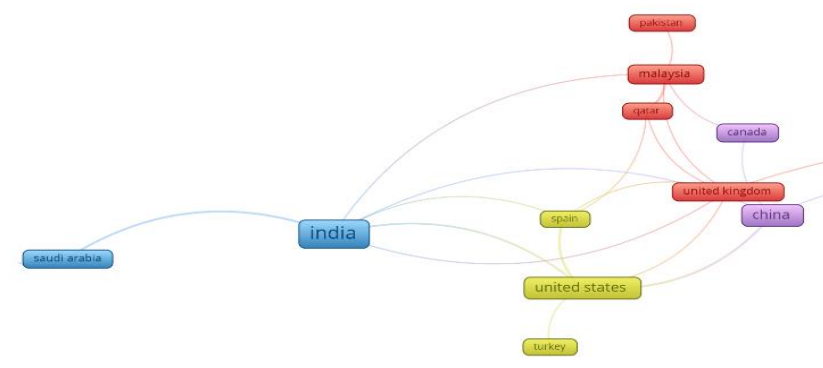

\section{Discussion}

Fig.5. Medical Image Co-Authorship Analysis

The data reveals that there are good number of researchers working on the medical image compression. India, USA and China are the country's leading in the research on this topic. IEEE and International Society of Optical Engineering are the sources with major number of citations and documents. Researchers worked majorly 
on the topics computerized tomography data compression, diagnostic imaging, digital image storage, image coding, image compression[7], image quality, image reconstruction[8]-[10], image segmentation[11], lossless compression, magnetic resonance imaging, medical image compression and medical image processing [4], [10], [12], [13].

\section{References:}

1. B. Goyal, A. Dogra, S. Agrawal, B. S. Sohi, and A. Sharma, "Image denoising review: From classical to state-of-the-art approaches," Inf. FUSION, vol. 55, pp. 220-244, Mar. 2020.

2. A. Gupta, D. Singh, and M. Kaur, "An efficient image encryption using non-dominated sorting genetic algorithm-III based 4-D chaotic maps Image encryption,” J. Ambient Intell. Humaniz. Comput., vol. 11, no. 3, SI, pp. 1309-1324, Mar. 2020.

3. M. Kaur, H. K. Gianey, D. Singh, and M. Sabharwal, "Multi-objective differential evolution based random forest for e-health applications," Mod. Phys. Lett. B, vol. 33, no. 5, Feb. 2019.

4. M. Kaur and V. Wasson, "ROI Based Medical Image Compression for Telemedicine Application," in Procedia Computer Science, 2015, vol. 70, pp. 579-585.

5. P. Roos, M. A. Viergever, M. C. A. Van Dijke, and J. H. Peters, "Reversible Intraframe Compression of Medical Images," IEEE Trans. Med. Imaging, vol. 7, no. 4, pp. 328-336, 1988.

6. K. Chen and T. V Ramabadran, "Near-Lossless Compression of Medical Images Through EntropyCoded DPCM," IEEE Trans. Med. Imaging, vol. 13, no. 3, pp. 538-548, 1994.

7. F. Y. Shih and Y.-T. Wu, "Robust watermarking and compression for medical images based on genetic algorithms," Inf. Sci. (Ny)., vol. 175, no. 3, pp. 200-216, 2005.

8. J. Ström and P. C. Cosman, "Medical image compression with lossless regions of interest," Signal Processing, vol. 59, no. 2, pp. 155-171, 1997.

9. Y.-G. Wu, "Medical image compression by sampling DCT coefficients," IEEE Trans. Inf. Technol. Biomed., vol. 6, no. 1, pp. 86-94, 2002.

10. S.-C. Tai, Y.-G. Wu, and C.-W. Lin, "An adaptive 3-D discrete cosine transform coder for medical image compression,” IEEE Trans. Inf. Technol. Biomed., vol. 4, no. 3, pp. 259-263, 2000.

11. G. Badshah, S.-C. Liew, J. M. Zain, and M. Ali, "Watermark Compression in Medical Image Watermarking Using Lempel-Ziv-Welch (LZW) Lossless Compression Technique," J. Digit. Imaging, vol. 29, no. 2, pp. 216-225, 2016.

12. [Z. Zuo, X. Lan, L. Deng, S. Yao, and X. Wang, "An improved medical image compression technique with lossless region of interest," Optik (Stuttg)., vol. 126, no. 21, pp. 2825-2831, 2015.

13. L. Shen and R. M. Rangayyan, "A segmentation-based lossless image coding method for highresolution medical image compression,” IEEE Trans. Med. Imaging, vol. 16, no. 3, pp. 301-307, 1997. 